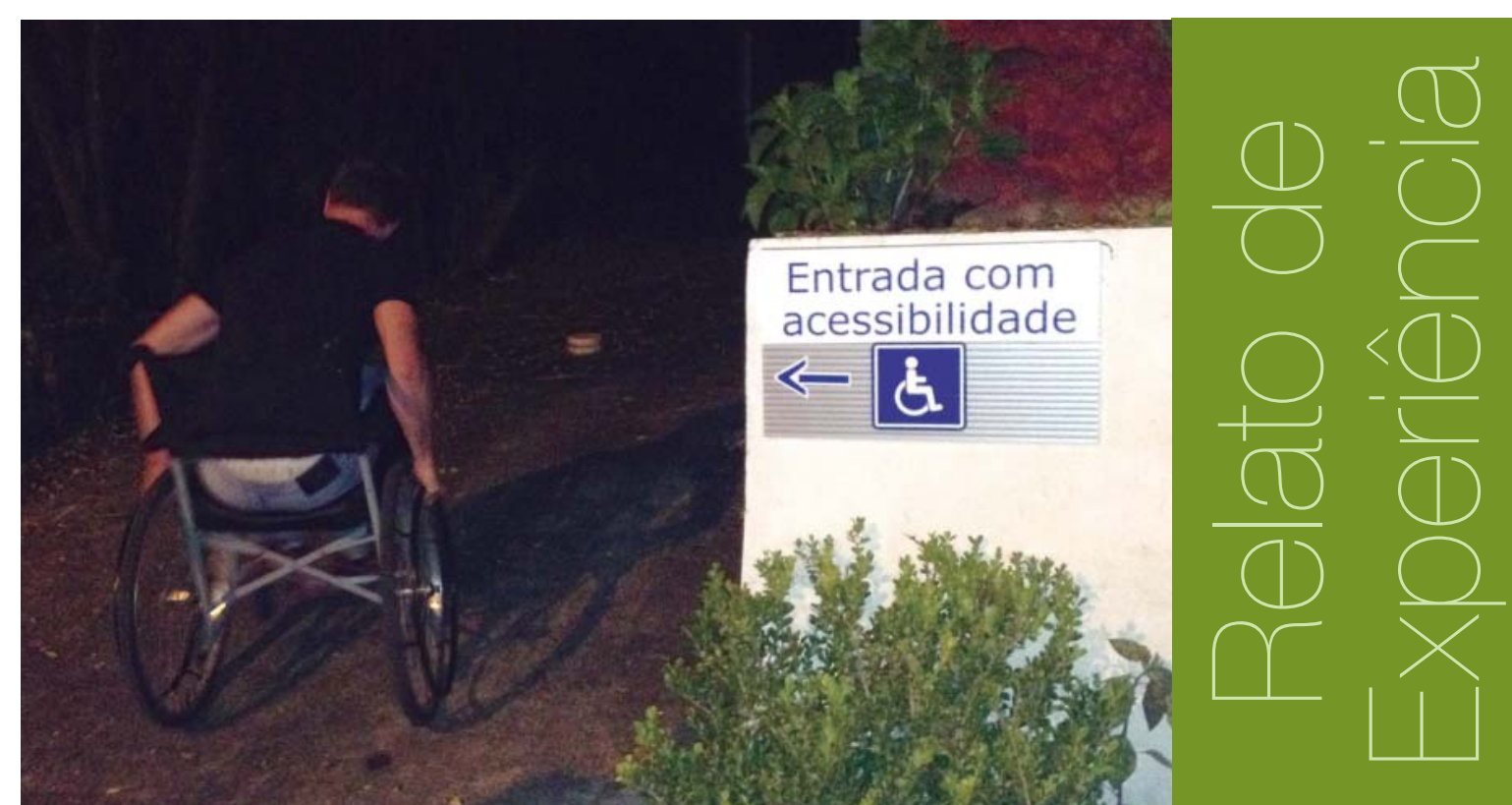

\title{
Acessibilidade: relato de experiência Educacional no IFSC São Carlos
}

Etianne Alves S. de Oliveira1 - etianne_oliveira@hotmail.com Israel da Silva Mota² - israel.mota@ifsc.edu.br Mauro Fernando Normberg Bohm³ - mauro.bohm@ifsc.edu.br Leonardo R. M. Pessanha - leonardo.pessanha@ifsp.edu.br

\section{RESUMO}

Questiona-se como dar cumprimento às legislações de acessibilidade fazendo-as alcançar seus objetivos. Por conta deste questionamento, este artigo relata uma experiência de ensino associado à extensão ocorrida no IFSC-São Carlos. Observou-se que os alunos tiveram melhor entendimento dos diferentes contextos da aplicação da legislação e garantia dos direitos civis dos portadores de deficiência e de necessidades especiais.

\section{PALAVRAS-CHAVE}

Acessibilidade. Educação. Construções.

\section{ABSTRACT}

Nowadays there is a worry about how to comply with accessibility legislation by effectively achieving its aims. This article presents a didactic experience report that applied the exploratory descriptive method with awareness, understanding of the legal, executive and practical contexts related to the accessibility of constructions. It was observed that the students had a better

\footnotetext{
1 Me. Engenharia de Produção, professora EBTT - IFSC

2 Esp. Gestão de Custos, professor EBTT - IFSC

3 Me. Arquitetura, professor EBTT - IFSC

4 Me. Engenharia Ambiental, professor EBTT - IFSP
} 
understanding of the different contexts of the application of the legislation and guarantee of the civil rights of the disabled people and with special needs.

\section{KEYWORDS}

Accessibility. Education. Construction.

\section{Relato de experiência}

Os Institutos Federais (IF), enquanto poder público, devem promover campanhas à população para conscientizá-la quanto à acessibilidade conforme Art. 24 da lei n¹0.098/2000 que aborda a promoção da acessibilidade. Os cursos de Formação Inicial e Continuada (FIC) de Acessibilidade nas Edificações e Técnico em Edificações trabalham 0 assunto. Este relato apresenta 0 uso da extensão como instrumento metodológico para alcançar os objetivos de ensino. Apresenta justificativa com embasamento teórico e objetivo; metodologia e resultados. Finaliza-se apresentando as considerações desta experiência.

\section{Justificativa}

No Brasil embora haja um longo caminho ainda a percorrer, há um histórico de ações nas questões da acessibilidade que buscam atender os portadores de deficiência e/ou de necessidade especial. Estas vêm sendo tomadas desde 1854, com a criação do Imperial Instituto dos Meninos Cegos e, em 1856, do Imperial Instituto dos Surdos-Mudos.

Em 1988 a Constituição abordou 0 tema e adotou a denominação de "pessoas portadoras de deficiência" estabelecendo uma denominação frente às variadas denominações existentes. Outro exemplo é a aprovação da Convenção da Organização das Nações Unidas sobre os direitos das Pessoas com Deficiência, em 2007, com a consequente criação da Emenda Constitucional.

Ações da sociedade civil organizada como a Sociedade Pestalozzi e as Associações de Pais e Amigos dos Excepcionais (APAE), Associação Brasileira Beneficente de Reabilitação (ABBR) e a Associação de Assistência à Criança Defeituosa (AACD) são exemplos de como a sociedade busca gerar igualdade de condições. Dentre as conquistas dos movimentos organizados, está a aceitação do novo modelo social em lugar do modelo positivista do saber médico existente até 0 século XIX (LANNA, 2010).

Atualmente, trabalham-se a supressão de barreiras físicas e sociais e o seu respaldo com medidas legislativas e políticas nas três esferas de governo que visam garantir os direitos civis e a igualdade de condições às pessoas portadoras de deficiência. Diante dessas várias legislações, questiona-se como dar cumprimento fazendo-as alcançar, efetivamente, seus objetivos.

Este trabalho apresenta um relato de experiência de ensino sobre 0 tema, de modo a sensibilizar os discentes para serem agentes transformadores da sociedade e fazendo-os compreender as diferentes variáveis que interferem na aplicabilidade da legislação de acessibilidade e nas práticas profissionais (Figura 1).

Figura 1: Oficina de acessibilidade em rota acessível conforme norma vigente.

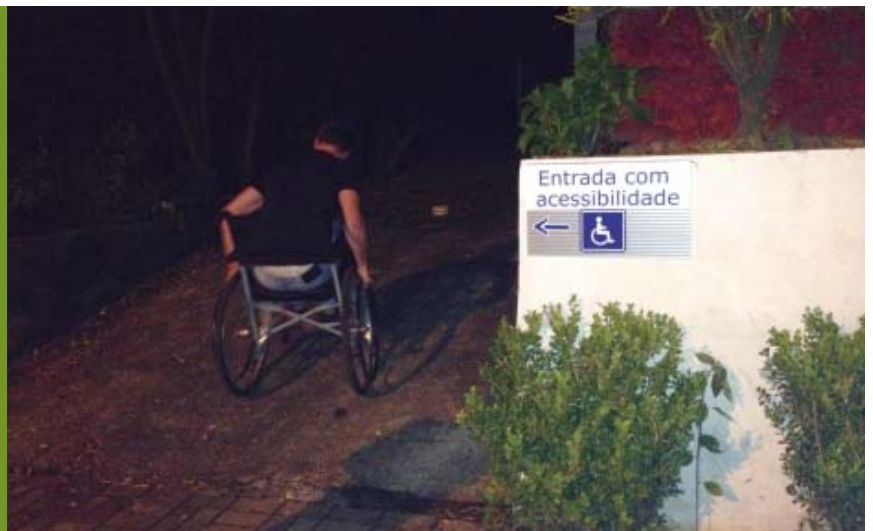


Entendemos que o conhecimento da legislação é apenas uma das variáveis que interferem na sua aplicabilidade, desta forma, propôs-se tratar o tema além da sala de aula, possibilitando um entendimento sobre o que a legislação não contempla.

\section{Método}

Utilizou-se 0 método exploratório descritivo com a abordagem qualitativa, com prática extensionista e consequente reflexão. Participaram 58 alunos de cursos FIC Acessibilidade nas Edificações, anos 2015 e 2016, e de uma turma do curso Técnico em Edificações 2015.

Foram três etapas: iniciou-se com aulas sobre 0 tema; após, houve simulações realizadas em meio urbano e em uma edificação, ambos parcialmente acessíveis; e finalizou-se com uma mesa redonda sobre 0 tema com a participação da sociedade.

\section{Resultados}

Inicialmente os alunos tiveram um embasamento teórico e jurídico com conceitos gerais e correlacionados ao tema. Conheceram os movimentos internacionais, como a Convenção sobre os Direitos das Pessoas com Deficiência da ONU (BRASIL, 2009). Estudaram a lei federal n¹0.098/2000 (BRASIL, 2000), o decreto n³.298/1999 (BRASIL, 1999), a lei 13.146/2015 (BRASIL, 2015) e as normas técnicas. Conheceram a metodologia de avaliação de acessibilidade física em edifícios públicos, adotada pelo Ministério Público de Santa Catarina.

Posteriormente, optou-se pela realização de oficinas para simular diversas situações reais (Figuras 2 e 3). Assim, foi possível identificar barreiras físicas, sociais e culturais presentes no município de São Carlos - SC. Foram organizadas duplas de cegos, surdos e mudos, usuários de bengala, cadeirantes e idosos. Cada dupla deveria desempenhar uma tarefa, interagindo com a sociedade e fazendo uso do espaço urbano e edificado.
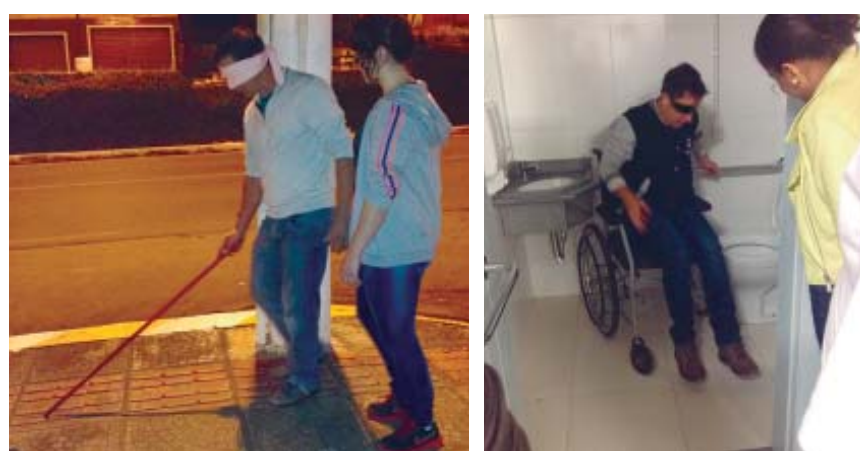

Figuras 2 e 3: Oficina de Acessibilidade Urbana.

Fonte: Autoria própria.

A última etapa foi a mesa redonda composta por uma empresa de construção; por deficientes físicos (cadeirantes, cegos e surdos-mudos); por agentes governamentais; por profissionais que atuam no mercado; por professores e por alunos já sensibilizados. Todos buscavam compreender as diferentes vertentes que interferem na acessibilidade (Figura 4).

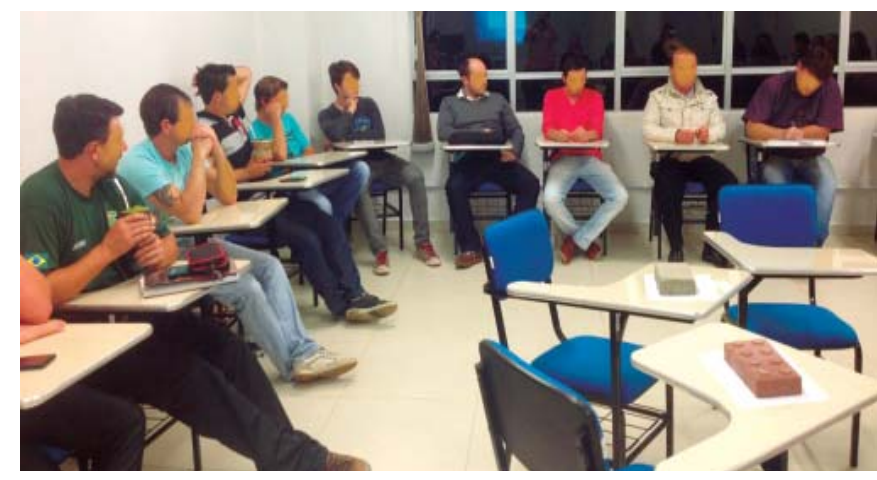

Figuras 3: Oficina de Acessibilidade Urbana e Mesa Redonda.

Fonte: Autoria própria. 
Foi possivel perceber incompatibilidade entre as normas, questionar os parâmetros das normas que atendem pessoas adultas, mas não atendem crianças deficientes, refletir sobre a diversidade humana e os padrões estabelecidos; ouviu-se relatos de melhorias em muitos aspectos permitindo autonomia e direitos iguais.

Um agente governamental apresentou dificuldades na adequação de edificações já consolidadas, garantia de direitos adquiridos e práticas construtivas tradicionais incompatíveis. Questionou-se: como executar acessibilidade nesses casos? Fernandes e Humberto (2013) afirmam que as pessoas com deficiência e necessidades especiais apresentam singularidades e são submetidas à exclusão ao longo da história.

Os profissionais que executam serviços relataram as dificuldades de aplicar a norma devido à interferência e desconhecimento dos contratantes (barreiras culturais). Sanfelice et al. (2014), em seu relato de experiência, citam a falta de infraestrutura acessível e a negligência da sociedade aos direitos dos deficientes.

Busca-se uma quebra de paradigmas de padrões culturais, sociais e físicos construídos para seres considerados iguais, padronizando-os, idealizando-os e não condizente com as peculiaridades humanas que nos fazem ser, por condição, diferentes uns dos outros.

Esta experiência didática permitiu aos alunos experimentarem barreiras pessoais, como: o medo, a insegurança e a falta de referencial; barreiras sociais, como: a indiferença, 0 preconceito e o desconhecimento sobre como agir em situações diferentes; e as barreiras físicas, ou seja, os obstáculos.

Observando as barreiras sociais, percebeu-se que a solidariedade e a colaboração social tornamse importantes fatores na efetivação da acessibilidade. Liveira (2013) corrobora esse achado ao afirmar que estudantes com limitações físico-motoras e sensoriais relatam comportamento diferenciado na universidade.

Quanto às barreiras físicas percebem-se dificuldades em sua correta aplicação, devido ao desconhecimento e/ou indiferença sobre 0 assunto (Figura 5).

Figura 4: Oficina de Acessibilidade na Edificação

Fonte: Autoria própria.

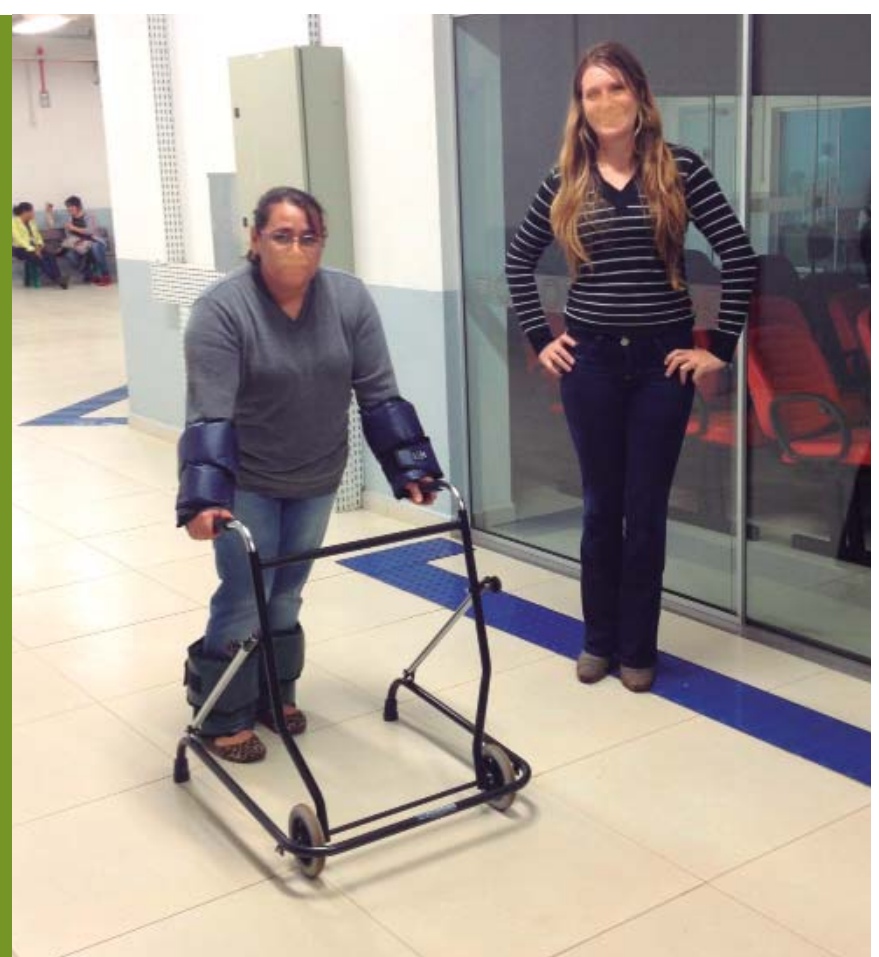

"Os diversos sujeitos que produzem e reproduzem suas vidas diárias estão em um cenário que está historicamente condicionado a uma estrutura social desumanizadora com limitações na própria estrutura" (FERNANDES; HUMBERTO, 2013). Estas barreiras culturais foram identificadas nos métodos construtivos adotados que impossibilitam a acessibilidade e situações de direitos consolidados. 


\section{Conclusão}

0 conceito de acessibilidade apresentado atualmente requer uma nova diversidade nos padrões de comunicação e nas relações sociais, um novo projetar arquitetônico e urbano, todos relacionados a mudanças culturais.

A experiência apresentou atividades típicas de sala de aula associada a atividades extensionistas. Os participantes puderam constatar que é na esfera cultural que as ideias preconcebidas geram processos de exclusão mais resistentes às mudanças propostas na legislação. Perceberam como o novo conceber arquitetônico e urbano e as novas formas de comunicação e expressão são fortemente influenciados por questões culturais que só a educação e a garantia dos direitos podem ser capazes de mudar.

\section{Referências}

BRASIL. Decreto № 3.298, de 20 de dezembro de 1999. Regulamenta a Lei № 7.853, de 24 de outubro de 1989, dispõe sobre a Política Nacional para a Integração da Pessoa Portadora de Deficiência, consolida as normas de proteção, e dá outras providências. Ministério da Justiça - MJ. Disponível em: http://www.planalto.gov.br/ccivil_03/decreto/d3298.htm. Acesso em: 27 jun. 2017.

BRASIL. Lei No 10.098, de 19 de dezembro de 2000. Estabelece normas gerais e critérios básicos para a promoção da acessibilidade das pessoas portadoras de deficiência ou com mobilidade reduzida, e dá outras providências. Ministério da Justiça - MJ . Disponível em: http://www.planalto.gov.br/ccivil_03/leis/L10098.htm. Acesso em: 27 jun. 2017.

BRASIL. Decreto $\mathbf{N}^{\circ} \mathbf{6 . 9 4 9}$, de 25 de agosto de 2009. Promulga a Convenção Internacional sobre os Direitos das Pessoas com Deficiência e seu Protocolo Facultativo, assinados em Nova York, em 30 de março de 2007. Ministério da Justiça - MJ. Disponível em: http://www.planalto. gov.br/ccivil_03/_ato2007-2010/2009/decreto/d6949.htm. Acesso em: 27 jun. 2017.

BRASIL. Lei N 13.146, de 6 julho de 2015. Institui a Lei Brasileira de Inclusão da Pessoa com Deficiência (Estatuto da Pessoa com Deficiência). Disponível em: http://www.planalto.gov.br/ ccivil_03/_ato2015-2018/2015/lei/l13146.htm. Acesso em: 27 jun. 2017.

FERNANDES, Idilia; HUMBERTO Lippo. Política de acessibilidade universal na sociedade contemporânea. Textos \& Contextos, Porto Alegre, v. 12, n. 2, p. 282- 291, jul./dez. 2013.

LANNA. Mário Cléber Martins Júnior. História do Movimento Político das Pessoas com Deficiência no Brasil. Brasília: Secretaria de Direitos Humanos. Secretaria Nacional de Promoção dos Direitos da Pessoa com Deficiência, 2010.

LIVEIRA, Cristina Borges de. Jovens deficientes na universidade: experiências de acessibilidade. Rev. Bras. Educ., Rio de Janeiro, v. 18, n. 55, p. 961-984, dez. 2013.

SANFELICE, Gustavo et al. A acessibilidade e as barreiras cotidianas: a percepção de Gabriel Feiten e de seus familiares. Espacio Abierto, v.23, n.3 pg.495 -514, 2014.

\section{Agradecimentos}

À APAE São Carlos e ADVOSC Chapecó. 